\title{
Recent studies of internal and surface nucleation in silicate glasses
}

\author{
By Edgar D. Zanotto and Vladimir M. Fokin \\ Vitreous Materials Laboratory (LaMaV), Department of Materials Engineering, \\ Federal University of São Carlos, 13565-905 São Carlos-SP, Brazil
}

Published online 29 January 2003

This article reviews recent findings on internal and surface nucleation in silicate glasses. The internal homogeneous nucleation rates sharply decrease and the induction times increase with the $T_{\mathrm{g}} / T_{\mathrm{L}}$ ratio $\left(T_{\mathrm{g}}\right.$ is the glass-transition temperature and $T_{\mathrm{L}}$ is the liquidus temperature). Only systems that have $T_{\mathrm{g}} / T_{\mathrm{L}}<0.58$ display measurable internal nucleation rates on a laboratory time-scale. Numerous tests of the classical nucleation theory have demonstrated that the theory fails to describe nucleation rates in glasses quantitatively. Possible explanations for this failure are tested and discussed. Surface nucleation depends strongly on the surface quality, e.g. tips, cracks and scratches, elastic stresses, foreign particles and surrounding atmosphere. The mechanisms of surface nucleation are still not fully understood, but some of the key factors are now known and the surface-nucleation density can thus be controlled for the development of sintered glasses or glass ceramics.

Keywords: nucleation; crystallization; silicate glass; glass surface

\section{Introduction and objectives}

When any glass is heated for a long enough time above the glass-transition range, $T_{\mathrm{g}}$, devitrification readily starts from surface nuclei. Surface crystallization is, therefore, often related to the undesired devitrification of glass articles during fabrication or use, or to the manufacture of some types of glass ceramics via sintering followed by crystallization of glass powders. Therefore, to prevent spontaneous devitrification, or to produce sintered glasses or glass ceramics, processing variables such as particle size distribution, heating rate and temperature must be strictly controlled to avoid premature crystallization, which would arrest viscous flow sintering (e.g. Zanotto \& Prado 2001; Prado et al. 2002). Even in the absence of catalysers, which are usually employed in the manufacture of commercial (cast) glass ceramics, a few glasses display spontaneous internal nucleation (in addition to surface nucleation). Some of these special systems are discussed in the first part of this review. In the second part, we summarize relevant tests of the classic nucleation theory (CNT) in glasses and discuss the possible reasons for its failure to describe nucleation rates. Finally, in the third part, we show evidence of the key factors that control the kinetics of surface nucleation in silicate glasses. Different theories, and modifications of the CNT, do indeed exist (e.g. Granasy \& James 1998, 1999a,b, 2000); however, due to

One contribution of 15 to a Discussion Meeting 'Nucleation control'. 
lack of space, in this review we focus mostly on our own research, which concentrated on the use and testing of the CNT.

\section{Theoretical background}

The steady-state homogeneous nucleation rate of spherical crystals can be written as (e.g. Gutzow \& Schmelzer 1995)

$$
\begin{gathered}
I_{\text {st }}=I_{0} \exp \left(-\frac{W^{*}+\Delta G_{\mathrm{D}}}{k T}\right), \quad I_{0}=2 N_{1} \frac{k T}{h}\left(\frac{a^{2} \sigma}{k T}\right)^{1 / 2}, \\
W^{*}=\frac{16 \pi}{3} \frac{\sigma^{3}}{\Delta G_{\mathrm{v}}^{2}},
\end{gathered}
$$

where $W^{*}$ is the thermodynamic barrier and $\Delta G_{\mathrm{D}}$ is the kinetic barrier for nucleation, $\sigma$ is the crystal-melt surface energy per unit area of crystal, $N_{1}$ is the number density of 'structural' units of size $a, k$ and $h$ are Boltzmann's and Planck's constants, respectively, and $\Delta G_{\mathrm{v}}$ is the thermodynamic driving force per unit volume of crystal. Within the classical theory of nucleation the temperature of maximum nucleation rate, $T_{\max }$, is determined mainly by thermodynamic and kinetic barriers. Fokin et al. (2002a) expressed these quantities as

$$
\left.\begin{array}{c}
\frac{W^{*}}{k T}=C_{1} \frac{1}{T_{\mathrm{r}}\left(1-T_{\mathrm{r}}\right)^{2}}, \quad C_{1} \equiv \frac{16 \pi}{3} \frac{\alpha^{3} \Delta H_{\mathrm{m}}}{R T_{\mathrm{m}}}, \quad T_{\mathrm{r}} \equiv \frac{T}{T_{\mathrm{m}}}, \\
\frac{\Delta G_{\mathrm{D}}(T)}{k T} \equiv \frac{\Delta G_{\eta}(T)}{k T}=\frac{C_{2}}{T_{\mathrm{r}}-T_{0 \mathrm{r}}}, \quad C_{2} \equiv \frac{2.31 B}{T_{\mathrm{m}}}, \\
T_{0 \mathrm{r}} \equiv \frac{T_{0}}{T_{\mathrm{m}}}, \quad C_{2}=C_{2}^{\prime}\left(T_{\mathrm{gr}}-T_{0 \mathrm{r}}\right),
\end{array}\right\}
$$

where $T_{\mathrm{m}}$ and $\Delta H_{\mathrm{m}}$ are the temperature and molar heat of melting, and $\alpha$ is an empirical coefficient obtained from fitting nucleation experiments to the CNT. With the approximation of size- and temperature-independent surface energy, $\alpha$ varies from 0.40 to 0.55 for silicate glasses (e.g. Manrich \& Zanotto 1995). $T_{0}$ and $B$ are empirical coefficients in the Vogel-Fulcher-Tammann equation that correspond to a temperature-dependent activation free energy for viscous flow $\Delta G_{\eta}(T)$, and $C_{2}^{\prime} \approx 30$.

To obtain equations (2.3) and (2.4), we assumed that $\Delta G_{\mathrm{D}} \cong \Delta G_{\eta}$. In addition, we used Turnbull's equation for the thermodynamic driving force, which neglects the difference in specific heat between the crystalline and liquid phases, and a semiempirical equation linking the crystal-melt surface energy with the molar heat of melting.

\section{Trends on crystal nucleation in silicate glasses}

Based on experimental nucleation data for silicate glasses, James (1989), Zanotto (1987) and Zanotto \& Weinberg (1989) observed that stoichiometric glasses having a reduced glass-transition temperature $T_{\mathrm{gr}}=T_{\mathrm{g}} / T_{\mathrm{L}}\left(T_{\mathrm{g}}\right.$ is the glass-transition temperature and $T_{\mathrm{L}}$ is the liquidus temperature) higher than 0.58-0.60 display only surface (mostly heterogeneous) crystallization, while glasses showing internal homogeneous 


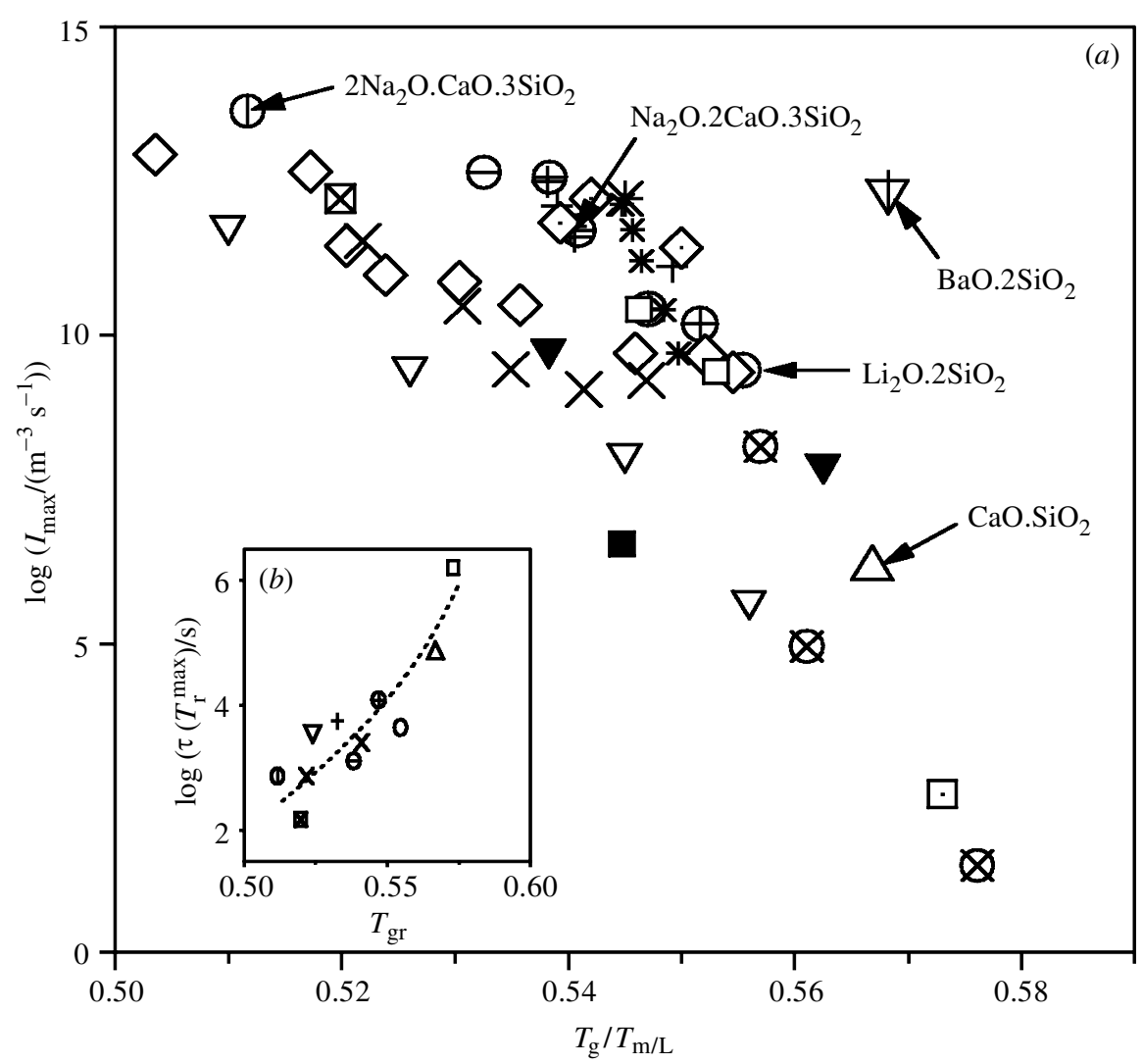

Figure 1. (a) Maximum nucleation rates against $T_{\mathrm{gr}}$ for 51 glasses of stoichiometric compositions and non-stoichiometric compositions. (b) Time-lag of nucleation at $T_{\max }$. (After Fokin et al. $(2002 a)$.)

nucleation have $T_{\mathrm{gr}}<0.58-0.60$. Since, at temperatures $T<T_{\mathrm{L}}$ the nucleation rate is always positive, the absence of volume nucleation data for glasses having $T_{\mathrm{gr}}>0.58$ indicates undetectable nucleation on a laboratory time-scale. When the reduced glass-transition temperature is relatively high $\left(T_{\mathrm{gr}}>0.58\right)$, the work of critical cluster formation at $T \sim T_{\mathrm{g}}$ is still too great to produce measurable nucleation. However, close to or on interfaces, the work of critical cluster formation and the viscosity are typically lower than bulk values causing surface crystallization. The transition from glasses demonstrating only surface crystallization to glasses showing volume nucleation is explained by an increase in the volume nucleation rate with decreasing $T_{\text {gr }}$, verified by Deubener (2000) and extended by Fokin et al. (2002a).

\section{(a) Experimental nucleation-rate data}

Figure $1 a$ (Fokin et al. 2002a) summarizes the data for the maximum nucleation rates, $I_{\max } \equiv I\left(T_{\max }\right)$, versus $T_{\text {gr }}$ for 51 glasses of stoichiometric and nonstoichiometric compositions belonging to eight silicate systems clearly showing the trend that $T_{\mathrm{gr}}$ increases with decreasing $I_{\max }$. In the relatively narrow range of $T_{\mathrm{gr}}(0.50$ to 0.58$)$ exhibited by these 51 glasses, the nucleation rate drops by 


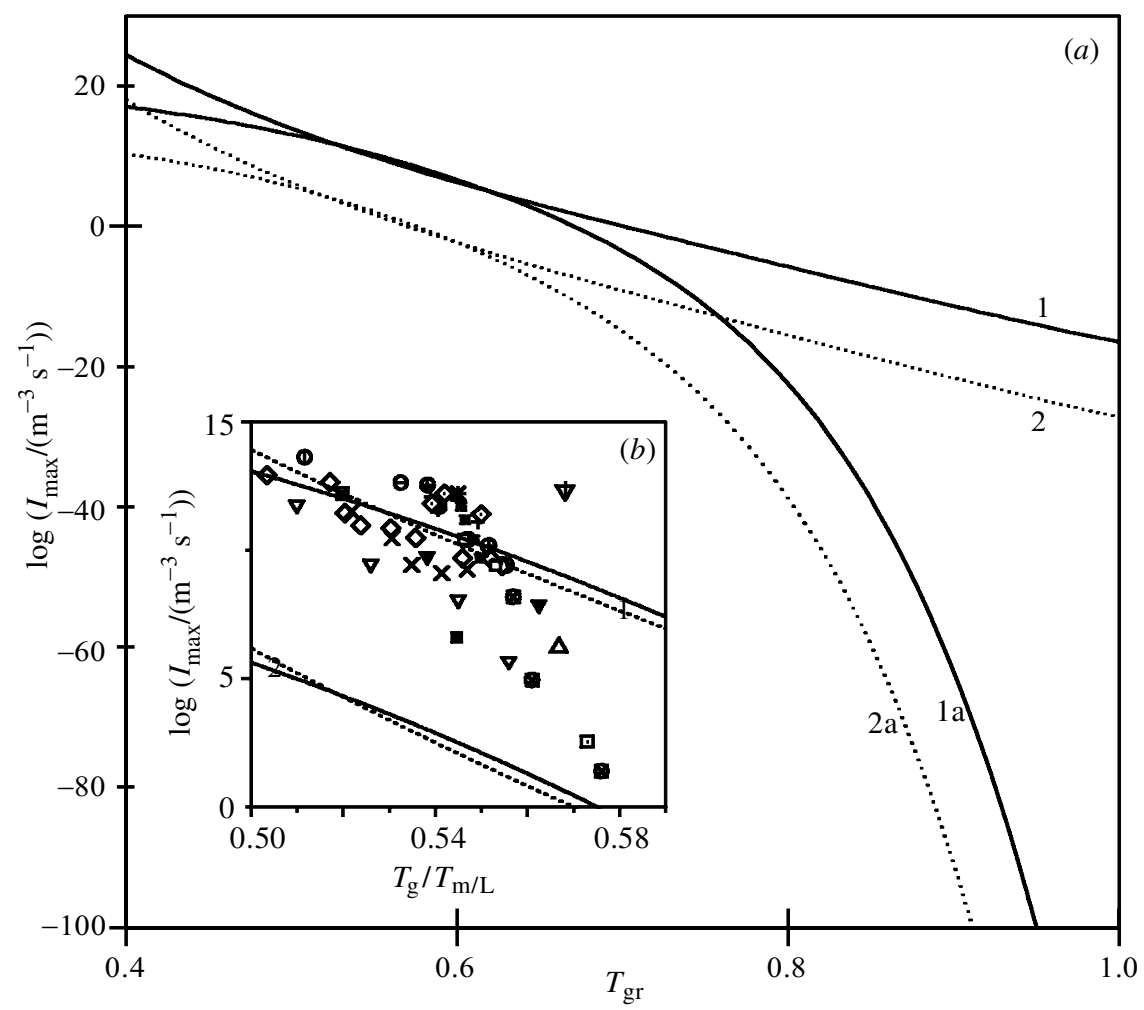

Figure 2. Maximum nucleation rate as a function of reduced glass-transition temperature. (a) The lines are calculated from the CNT with $T_{0 \mathrm{r}}=0.4(1,2)$ and $C_{2}=4.5(1 \mathrm{a}, 2 \mathrm{a})$ for different thermodynamic barriers: $C_{1}=5(1,1 \mathrm{a}), C_{1}=7(2,2 \mathrm{a})$. (b) Points refer to experimental data. The lines are calculated from the CNT with $C_{1}=4.5(1), C_{1}=6.5$ (2). Solid lines, $C_{2}=4.5$ and $T_{0 \mathrm{r}}=T_{\mathrm{gr}}-C_{2} / 30$; dashed lines, $T_{0 \mathrm{r}}=0.4$. (After Fokin et al. $(2002 a)$.)

ca. 12 orders of magnitude! Hence, nucleation becomes practically undetectable at $T_{\text {gr }}>0.58$. This finding corroborates the proposals of James (1989), Zanotto (1987) and Zanotto \& Weinberg (1989). The drastic drop in $I_{\max }$ is accompanied by an increase in the time lag of nucleation at $T_{\max }$ (see figure 1b) (Fokin et al. 2002a).

\section{(b) Analysis with CNT}

Because equation (2.4) has two independent parameters, $C_{2}$ and $T_{0 \mathrm{r}}$, the viscosity and, correspondingly, $T_{\text {gr }}$ may be varied in two different ways, by keeping either $C_{2}$ or $T_{0 \mathrm{r}}$ fixed. However, in the most interesting range of temperatures $\left(0.5<T_{\mathrm{r}}<0.6\right)$, these different ways of varying $T_{\text {gr }}$ lead to similar results. Thus, $T_{\text {gr }}$ can be treated as the decisive quantity for an understanding of general trends regarding the nucleation rate.

The lines in figure 2 show the values of $I\left(T_{\max }\right)$ against $T_{\mathrm{gr}}$, taken from $I\left(T_{\mathrm{r}}\right)$ curves calculated by (2.1), (2.3) and (2.4) for different $T_{\mathrm{gr}}$ and, correspondingly, for different kinetic barriers, using the theoretical pre-exponential term $I_{0}=10^{42} \mathrm{~m}^{-3} \mathrm{~s}^{-1}$.

According to the CNT, a decrease in temperature produces two effects: a decrease in the thermodynamic barrier (leading to a higher nucleation rate), and an increase in 
the kinetic inhibition of nucleation due to an increase in viscosity (resulting in a lower nucleation rate), producing a maximum in the steady-state nucleation rate well below $T_{\mathrm{m}}$. Within CNT, $T_{\mathrm{r}}=1 / 3$ is a lower limit of $T_{\mathrm{r}}^{\max }$ obtained when the value of the kinetic barrier tends to zero. However, the kinetic inhibition of nucleation in glassforming silicate melts is high. If $T_{\mathrm{gr}}$ increases, the kinetic inhibition of nucleation occurs at higher temperatures and, thus, at higher values of the thermodynamic barrier to nucleation, shifting $T_{\mathrm{r}}^{\max }=T_{\max } / T_{\mathrm{L}}$ above $1 / 3$ and decreasing $I\left(T_{\max }\right)$ (e.g. Filipovich et al. 1983). This is shown in figure $2 a$. This trend is independent of how the parameter $T_{\mathrm{gr}}$ is changed. Quantitatively, the results obtained by two different methods of varying $T_{\text {gr }}$ (figure $2 a$, curves 1,2 and $1 \mathrm{a}, 2 \mathrm{a}$ ) show significant differences, which are, however, most pronounced for $T_{\mathrm{gr}}>0.7-0.8$. In the range of interest $\left(0.5<T_{\text {gr }}<0.6\right)$, however, the differences are very slight. Figure $2 b$ shows that the experimental data on homogeneous nucleation are bounded by $\log I_{\max }$ versus $T_{\text {gr }}$ lines, calculated using reasonable values of $C_{1}$ and $C_{2}$ and different ways of varying $T_{\mathrm{gr}}$.

The experimental $\Delta G$ are bounded by the expressions of Turnbull (upper bound, used here) and Hoffman (lower bound). Moreover, nucleation of metastable phases is possible, such as $\mathrm{BaO}-2 \mathrm{SiO}_{2}$, shown by Lewis et al. (1979). The data point relating to this glass is quite distant from the others. Additionally, thermodynamic barriers (see equation (2.3)) vary substantially for different glasses. The trends observed must therefore be analysed within reasonable limits. Nevertheless, both the experimental data and the calculated curves show a clear decrease in $I_{\max }$ with $T_{\mathrm{gr}}$. Thus, although the CNT does not provide a perfect explanation of the $I_{\max }$-versus- $T_{\mathrm{gr}}$ dependence, it does give a correct trend.

Only ca. $10 \%$ of the glass-forming substances vitrified at normal cooling rates have $T_{\text {gr }}<0.6$ (Gutzow \& Schmelzer 1995); hence, only these $10 \%$ show volume nucleation on a laboratory time-scale. In the case of glass-forming metallic alloys, however, most compositions are located at $T_{\mathrm{g}} / T_{\mathrm{L}}<0.6$, thus nucleating copiously. The high nucleation and growth rates explain why metallic alloys are reluctant glass-formers compared with the typical glass-formers.

\section{Testing the classical nucleation theory for internal homogeneous nucleation}

Over the past 20 years, the CNT has been exhaustively tested by several authors, with some stoichiometric silicate glasses that show internal nucleation (e.g. James 1982, 1989; Manrich \& Zanotto 1995). In these tests, it was generally assumed that viscous flow controls molecular transport at the nucleus-matrix interface; for this case, equation (2.1) can be written as

$$
\begin{aligned}
I_{\mathrm{st}} & =K_{\eta} \frac{1}{\eta} \exp \left(-\frac{W^{*}}{k T}\right), \\
K_{\eta} & \equiv \frac{1}{2} \frac{N_{1}^{2 / 3}(k T \sigma)^{1 / 2}}{l^{3}}=I_{0} \frac{h}{4 l^{3}},
\end{aligned}
$$

where $l$ has a value of the order of the $\mathrm{Si}-\mathrm{O}$ bound length and $K_{\eta}$ is only weakly dependent on temperature. 
Table 1. Ratio of experimental and theoretical pre-exponential and surface energy calculated by the CNT for different glasses

(Values for $\Delta C_{p}=0$ calculated using Turnbull's approximation.)

\begin{tabular}{|c|c|c|c|c|}
\hline \multirow[b]{2}{*}{ glass } & \multicolumn{2}{|c|}{$\Delta C_{p}=0$} & \multicolumn{2}{|c|}{$C_{p}=f(T)$} \\
\hline & $\log \left(\frac{K_{\eta}^{\text {exp }}}{K_{\eta}^{\text {theo }}}\right)$ & $\sigma\left(\mathrm{J} \mathrm{m}^{-2}\right)$ & $\log \left(\frac{K_{\eta}^{\exp }}{K_{\eta}^{\text {theo }}}\right)$ & $\sigma\left(\mathrm{J} \mathrm{m}^{-2}\right)$ \\
\hline $\mathrm{Li}_{2} \mathrm{O} .2 \mathrm{SiO}_{2}$ & 15 & 0.19 & 19 & 0.20 \\
\hline $\mathrm{Na}_{2} \mathrm{O} .2 \mathrm{CaO} .3 \mathrm{SiO}_{2}$ & 18 & 0.17 & 72 & 0.19 \\
\hline $2 \mathrm{Na}_{2} \mathrm{O} \cdot \mathrm{CaO} \cdot 3 \mathrm{SiO}_{2}$ & 27 & 0.15 & 139 & 0.17 \\
\hline
\end{tabular}

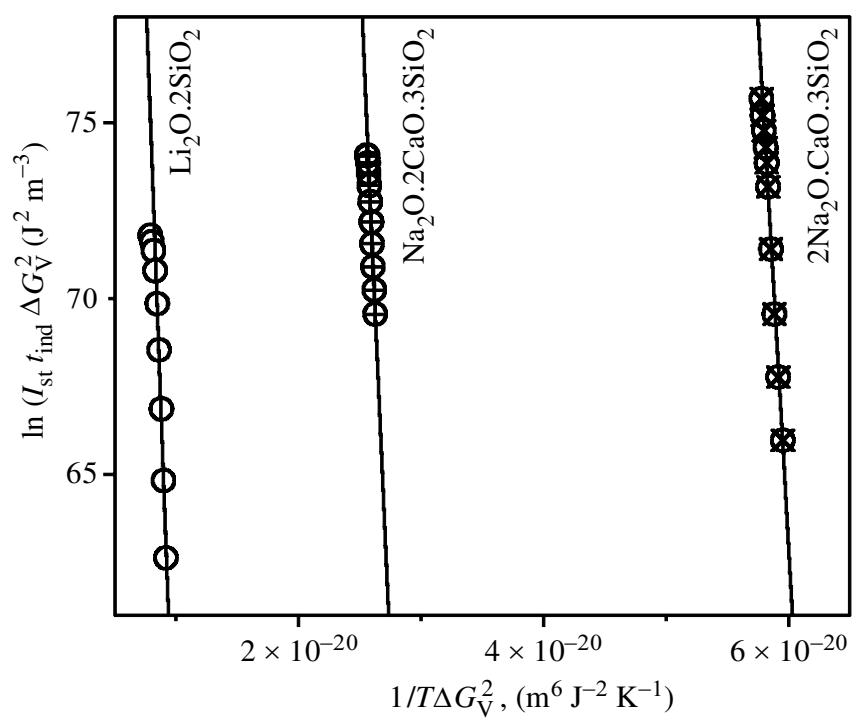

Figure 3. Plots of $\ln \left(I_{\mathrm{st}} t_{\text {ind }} \Delta G_{\mathrm{v}}^{2}\right)$ against $1 / T \Delta G_{\mathrm{v}}^{2}$ for three stoichiometric glasses.

Linear fit for $T>T_{\mathrm{g}} . \Delta G_{\mathrm{v}}$ corresponds to $\Delta C_{p}=f(T)$.

The results of a few such tests were summarized by Manrich \& Zanotto (1995). Using $\eta(T)$ and $\Delta G(T)$ data, and assuming a constant surface energy, which is obtained by fitting the temperature of maximum nucleation rate to the theoretical $T_{\max }$, the CNT predicts the temperature dependence of the nucleation rates well, but shows a colossal discrepancy in the actual nucleation rates. The theoretical and experimental nucleation rates differ by more than 20 orders of magnitude!

Weinberg \& Zanotto (1989) assumed that the temperature dependence of the induction times, $t_{\text {ind }}$, reflects that of molecular transport in the nucleation process, making it possible to test CNT while avoiding assumptions about the viscosity. Therefore, equation (2.1) reads

$$
I_{\mathrm{st}}=K_{\tau} \frac{1}{\Delta G_{\mathrm{v}}^{2} t_{\mathrm{ind}}} \exp \left(-\frac{W^{*}}{k T}\right),
$$


where

$$
K_{\tau} \equiv \frac{16}{3} N_{1}^{2}(k T)^{1 / 2} \sigma^{3 / 2}=\frac{8}{3} \frac{h \sigma}{a^{4}} I_{0},
$$

and $K_{\tau}$ is weakly dependent on temperature. Figure 3 shows $\ln \left(I_{\mathrm{st}} t_{\mathrm{ind}} \Delta G_{\mathrm{v}}^{2}\right)$ versus $1 / T \Delta G_{\mathrm{v}}^{2}$ plots for three stoichiometric glasses. Table 1 presents the $K_{\eta}^{\exp } / K_{\eta}^{\text {theo }}$ ratio and the surface energy $\sigma$, calculated from figure 3, for temperatures above the glasstransition temperature (there is an inflection, not shown, at $T_{\mathrm{g}}$ ). The original form of CNT, which assumes a temperature- and size-independent surface energy, was used in this study. Different approximations were employed for the thermodynamic driving force

$$
\Delta G=-\frac{\Delta H_{\mathrm{m}}}{T_{\mathrm{m}}}\left(T_{\mathrm{m}}-T\right)-\int_{T}^{T_{\mathrm{m}}} \Delta C_{p} \mathrm{~d} T^{\prime}+T \int_{T}^{T_{\mathrm{m}}} \frac{\Delta C_{p}}{T^{\prime}} \mathrm{d} T^{\prime},
$$

where $\Delta G_{\mathrm{v}}=\Delta G / V, \Delta H_{\mathrm{m}}$ is the latent heat of melting per mole, $T_{\mathrm{m}}$ is the melting point, $\Delta C_{p}=C_{p}^{\mathrm{C}}-C_{p}^{\mathrm{L}}(<0)$ is the difference in specific heat between the crystalline and liquid phases and $V$ is the molecular volume.

The $K_{\tau}^{\exp } / K_{\tau}^{\text {theo }}$ ratio characterizes the discrepancy between theory and experiment, and it is strongly affected by the choice of $\Delta G\left(\Delta C_{p}=0\right.$ or $\left.\Delta C_{p}=f(T)\right)$. The value of $K_{\tau}^{\exp } / K_{\tau}^{\text {theo }}$ dramatically increases as one passes from Turnbull's to Hoffman's approximation for $\Delta G(T)$. Turnbull's approximation, which corresponds to the upper limit for $\Delta G(T)$, gives the lowest discrepancies. In any case, with any reasonable approximation for $\Delta G(T)$, the discrepancy between theory and experiment is quite considerable.

If one assumes a constant nucleus-liquid surface energy and uses either the viscosity or the induction time to account for the molecular rearrangements at the interface, drastic discrepancies result between theoretical and experimental nucleation-rate values, regardless of the expression used to estimate the driving force. These findings also hold true for the experimental $\Delta G$, which is bounded by Turnbull's and Hoffman's equations.

In the following sections we test three other possible explanations for the CNT failure: metastable phase precipitation in the early stages of nucleation; compositional shifts of the crystal nuclei; and a possible dependence of the surface energy on temperature and nucleus size.

\section{(a) Metastable phase formation}

A possible explanation for the apparent failure of CNT is the early precipitation of metastable crystalline phases having a lower surface energy, which may induce heterogeneous nucleation of the stable phase. Alternatively, however, metastable phases may nucleate independently and transform to the stable phase at later times. Some authors have suggested the appearance of metastable phases in $\mathrm{Li}_{2} \mathrm{O} .2 \mathrm{SiO}_{2}$ $\left(\mathrm{LS}_{2}\right)$ glass, for example, in contrast to others, who were unable to detect any metastable phase prior to stable $\mathrm{LS}_{2}$ crystal. Although many techniques have been used, e.g. small-angle X-ray scattering, dielectric relaxation, Raman spectroscopy and X-ray photoelectron spectroscopy (Hench et al. 1971; Freiman \& Hench 1968; Joseph \& Pye 1986, respectively), they provide only indirect evidence, which contributes to the continuing uncertainty. Reviews on this issue were published by Zanotto (1997) and Burgner et al. (2000). 
Even studies focusing on a direct technique, transmission electron microscopy (TEM), are controversial. James \& Keown (1974), for instance, studied the nucleation of an (almost) stoichiometric lithium disilicate glass heat treated in the temperature range of $450-490{ }^{\circ} \mathrm{C}$ for periods of up to $150 \mathrm{~h}$. Electron diffraction patterns showed only the stable phase $\mathrm{LS}_{2}$. On the other hand, Deubener et al. (1993) concluded that a transient phase appears as a precursor to the stable $\mathrm{LS}_{2}$ phase in a (slightly hyper-stoichiometric) 33.5 mol.\% glass treated at $454{ }^{\circ} \mathrm{C}$ for $7 \mathrm{~h}$ and $40 \mathrm{~h}$. However, J. Deubener (1994, personal communication) later mentioned that their results were subject to uncertainty due to fast degradation of the crystals under the electron beam. A phase different from $\mathrm{LS}_{2}$ was also observed by Soares (1997) and Zanotto (1997) in a hypostoichiometric $32.5 \mathrm{~mol} \% \mathrm{Li}_{2} \mathrm{O}$ nucleated at $454{ }^{\circ} \mathrm{C}$ for 5-20 h. However, the diffraction patterns were obtained along only one zone axis, which did not allow for the proper identification of the crystals. In this case also, the crystals became amorphous in a few minutes. Therefore, until recently, there was some evidence that different metastable phases formed during the early stages of crystallization in $\mathrm{LS}_{2}$ glasses, but the nature and role that metastable phases played with respect to the crystallization mechanism remained unclear. Regarding this latter issue, in a detailed study of the overall crystallization kinetics of stoichiometric $\mathrm{LS}_{2}$ glass, Zanotto \& Leite (1996) concluded that any metastable phase, if present at all, had no significant impact on the crystallization path of the stable $\mathrm{LS}_{2}$ crystal.

Recently, Soares et al. (2002) investigated the early (less than $1 \%$ crystallized fraction) and intermediate (ca.5-10\%) stages of crystallization of hypostoichiometric, stoichiometric and hyper-stoichiometric lithium disilicate glasses by TEM/selected area diffraction (SAD). In all their samples, treated from $2.5 \mathrm{~h}$ to $120 \mathrm{~h}$ at $454{ }^{\circ} \mathrm{C}\left(T_{\mathrm{g}}\right.$ is close to the temperature of maximum nucleation), two different crystalline phases, $\mathrm{LS}_{2}$ and LS, were clearly indexed by SAD. These are stable phases in the hyperstoichiometric glass, but hypostoichiometric and stoichiometric glasses may follow two possible paths during nucleation: (i) $\mathrm{LS}_{2}$ crystals may nucleate heterogeneously on top of the LS crystals. This path may partly explain the failure of the CNT. (ii) There is simultaneous homogeneous nucleation of $\mathrm{LS}_{2}$ and LS, but LS disappears during the heat treatment. Thus, LS is a metastable phase that does not interfere with the nucleation path of the $\mathrm{LS}_{2}$.

Despite the poor statistics (only half-a-dozen crystals were detected in each TEM sample), there was no evidence that LS crystals induce the heterogeneous nucleation of $\mathrm{LS}_{2}$. In addition, there was plenty of glass remaining even after $120 \mathrm{~h}$; thus, thermodynamic equilibrium had not yet been reached. However, LS crystals should be metastable, since the calculations of B. A. Shakhmatkin and N. M. Vedishcheva (2001, personal communication) demonstrate that the thermodynamic driving force for LS crystallization in $\mathrm{LS}_{2}$ glass is $c a .10 \%$ less than the one for $\mathrm{LS}_{2}$ crystals; otherwise, the phase diagram would be incorrect!

TEM then provided clear evidence that a second phase, LS, nucleates concurrently with the stable phase, $\mathrm{LS}_{2}$, in stoichiometric and hypostoichiometric lithium disilicate glasses treated at $T_{\mathrm{g}} \sim 454{ }^{\circ} \mathrm{C}$ for long times. No phases other than di- and metasilicates appeared. There was no evidence of heterogeneous nucleation of lithium disilicate on top of the lithium metasilicate. So this mechanism does not explain the discrepancy of the CNT. 


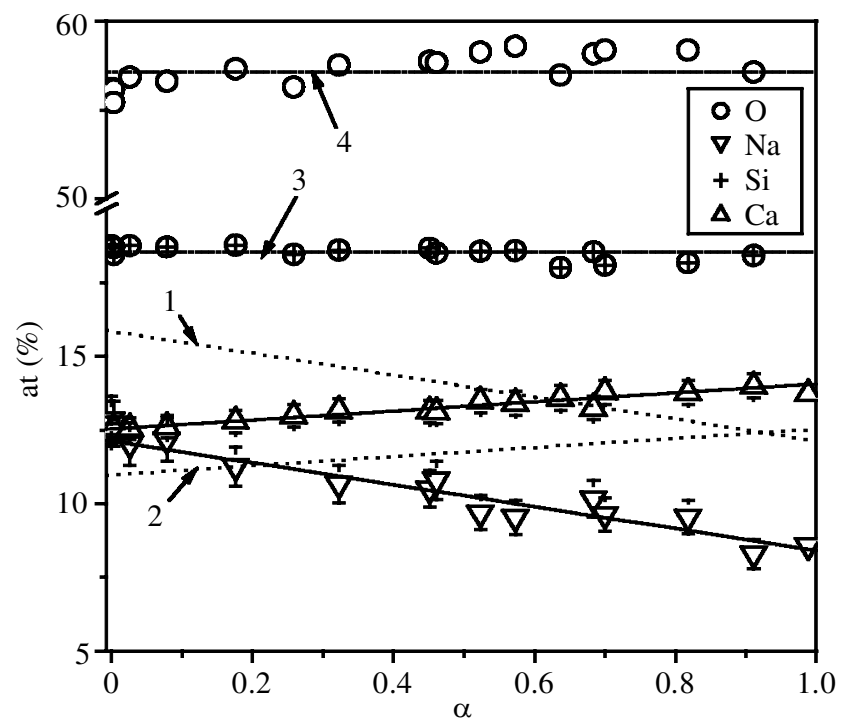

Figure 4. Glass $1 \mathrm{Na}_{2} \mathrm{O} .2 \mathrm{CaO} .3 \mathrm{SiO}_{2}$ : compositional variation against volume fraction crystallized at $650{ }^{\circ} \mathrm{C}$. Glass (points) measured by EDS; crystals (dotted lines 1 and 2 denote Na and Ca, respectively) calculated from the parent glass composition and EDS measurements. Solid lines fit the experimental data. Dashed lines $3(\mathrm{Si})$ and $4(\mathrm{O})$ correspond to the parent glass composition. (After Fokin et al. (2002b).)

\section{(b) Compositional shifts of crystal nuclei}

While metastable phases have crystallographic structures unlike those of the stable phase, within certain limits, solid solutions ('ss's) can continuously change the composition of a given crystallographic system during phase transformation. Hence, generally speaking, the composition and, consequently, the properties of the critical nuclei may deviate considerably from those of the corresponding macro phase.

Fokin et al. $(1999,2002 b)$ recently observed that such is, indeed, the case in a stoichiometric $1 \mathrm{Na}_{2} \mathrm{O} .2 \mathrm{CaO} .3 \mathrm{SiO}_{2}$ glass $\left(\mathrm{N}_{1} \mathrm{C}_{2} \mathrm{~S}_{3}\right)$ that displays homogeneous internal nucleation. Phase transformation in this glass proceeds through the formation of ss crystals, which are enriched in sodium relative to the parent glass. During crystallization, the composition of the ss crystals continuously approaches the stoichiometric one. The deviation of the nuclei composition from that of the parent glass forms sodium-poor diffusion fields in their vicinity, and nucleation terminates in an early stage of phase transformation. This is consistent with the finding of Potapov et al. (2000), who demonstrated that the nucleation rate in glasses close to $\mathrm{N}_{1} \mathrm{C}_{2} \mathrm{~S}_{3}$ is very sensitive to the parent glass composition and decreases with decreasing sodium oxide content.

The evolution of crystal and glass compositions and the corresponding change of the lattice parameter are shown in figures 4 and 5. Extrapolating the change of crystal composition to zero time (or zero volume fraction crystallized, $\alpha=0$ ) suggests that the critical clusters are also enriched in sodium. The deviation of the nuclei composition from the stoichiometric one diminishes the thermodynamic driving force for crystallization, $\Delta G_{\mathrm{V}}$, and has to magnify the kinetic barrier for nucleation. Since the nucleation of sodium-rich ss crystals occurs instead of the expected stoichiometric 


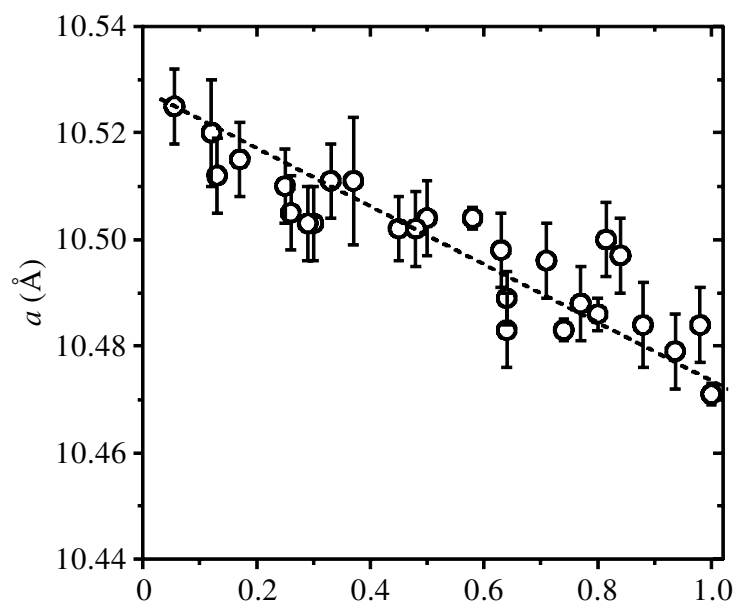

Figure 5. Parameter $a$ of the hexagonal crystal cell against volume fraction crystallized at $650{ }^{\circ} \mathrm{C}$. (After Fokin et al. (2002b).)

crystals, the decrease in the driving force for crystallization must be compensated for by a decrease in surface energy in equation (2.2) for the thermodynamic barrier.

The present interpretation of the nucleation kinetics in $\mathrm{N}_{1} \mathrm{C}_{2} \mathrm{~S}_{3}$ glass is consistent with Ostwald's rule of stages, generalized by Schmelzer et al. (2000) as

those classes of critical clusters determine the transformation process corresponding to a minimum work of critical cluster formation-as compared with all other possible alternative structures and compositions which may be formed at the given thermodynamic constraints.

Since ss formation is a common phenomenon in silicate systems, it is important to keep in mind when analysing nucleation kinetics that the composition of the critical nuclei and, correspondingly, their thermodynamic driving force and surface energy, may differ considerably from those of the final macrophase. In some cases, as in the $\mathrm{N}_{1} \mathrm{C}_{2} \mathrm{~S}_{3}$ glass, this fact may partly explain the failure of the CNT to predict nucleation rates.

\section{(c) Temperature- and size-dependent nucleus-liquid surface energy}

We have already mentioned that CNT fails when the nucleus-liquid surface energy is treated as a size-independent (capillarity approximation) and temperatureindependent property, i.e. $\sigma(r, T)=\sigma_{\infty}$. This discrepancy can be avoided by calculating a surface energy from experimental nucleation-rate data at each temperature, using the theoretical pre-exponential factor. The surface energy obtained by this method slightly increases with temperature $\left(\mathrm{d} \sigma / \mathrm{d} t \sim(0.06-0.16) \times 10^{-3} \mathrm{~J} \mathrm{~m}^{-2} \mathrm{~K}\right)$, as observed for metals (Turnbull 1952; Miyazawa \& Pound 1974) and silicate glasses (e.g. Fokin \& Zanotto 2000).

Since the surface energy calculated from nucleation data refers to that for critical nuclei whose size depends on temperature, the fitted $\sigma(T)$ dependence arises from two factors, the temperature dependence of surface energy for a planar interface, $\mathrm{d} \sigma_{\infty} / \mathrm{d} T$, and the size dependence of surface energy. However, according to Rusanov 


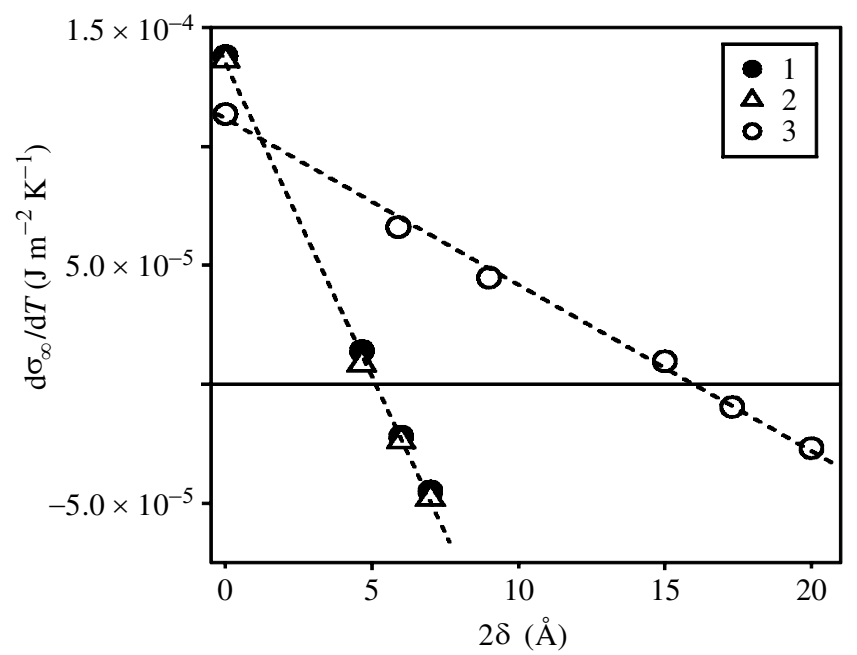

Figure 6. Average values of $\mathrm{d} \sigma_{\infty} / \mathrm{d} T$ against Tolman's parameter for $\mathrm{Li}_{2} \mathrm{O} .2 \mathrm{SiO}_{2}(1,2)$ and $\mathrm{Na}_{2} \mathrm{O} .2 \mathrm{CaO} .3 \mathrm{SiO}_{2}$ (3) crystals in parent glasses having the same compositions. The kinetic barrier for nucleation was estimated from time lag of nucleation $(2,3)$ and viscosity $(1)$. (Reproduced with permission from Fokin \& Zanotto (2000).)

(1978) and Gutzow et al. (1985), when the molar volume of the liquid phase is higher than that of the crystal phase, as is most typical, $\mathrm{d} \sigma_{\infty} / \mathrm{d} T$ should be negative.

To decouple size and temperature effects, Fokin \& Zanotto (2000) took into account the size dependence of $\sigma$ using, as a first approximation, an equation derived by Tolman (1949) for a liquid drop with radius $R$,

$$
\sigma(R)=\frac{\sigma_{\infty}}{(1+2 \delta) / R}
$$

where $\delta$ is Tolman's parameter, which characterizes the (unknown) width of the interfacial region between the coexisting phases.

The work of forming a spherical nucleus may thus be written as

$$
W=\frac{4}{3} \pi R^{3} \Delta G_{\mathrm{v}}-4 \pi \frac{R^{3} \sigma_{\infty}}{R+2 \delta} .
$$

The critical radius can be found from the condition $(\partial W / \partial R)_{R=R^{*}}=0$, where

$$
R^{*}=\frac{\left(\sigma_{\infty}-2 \Delta G_{\mathrm{v}} \delta\right)+\left(\sigma_{\infty}^{2}+2 \Delta G_{\mathrm{v}} \delta \sigma_{\infty}\right)^{1 / 2}}{\Delta G_{\mathrm{v}}} .
$$

Figure 6 shows the average values of $\mathrm{d} \sigma_{\infty} / \mathrm{d} T$ versus Tolman's parameter. The fits of $\sigma_{\infty}$ to experimental nucleation data for $\mathrm{L}_{2} \mathrm{O} .2 \mathrm{SiO}_{2}$ and $\mathrm{Na}_{2} \mathrm{O} \cdot \mathrm{CaO} .3 \mathrm{SiO}_{2}$ glasses were performed for different values of $\delta$. As $\delta$ increased, $\mathrm{d} \sigma_{\infty} / \mathrm{d} T$ progressively decreased, becoming negative at $\delta>2.6 \times 10^{-10} \mathrm{~m}\left(\mathrm{LS}_{2}\right.$ glass $)$ and $8 \times 10^{-10} \mathrm{~m}$ $\left(\mathrm{NC}_{2} \mathrm{~S}_{3}\right.$ glass). Thus, reasonable values of the Tolman parameter may be chosen so that $\sigma_{\infty}$ increases with decreasing temperature, in line with the predictions of Rusanov (1978) and Gutzow et al. (1985).

Essentially all methods to determine the nucleus-liquid surface energy are based on nucleation experiments, involving certain additional assumptions. Recently, Fokin 
et al. (2000) estimated surface energy without using the nucleation-rate data directly, but instead using the dissolution of subcritical nuclei with an increase in temperature. However, the values of the surface energy determined by this method, using the thermodynamic driving force of crystallization of the macro phase, were much higher than those obtained from a direct fit of nucleation-rate data to CNT. This discrepancy may be eliminated if a reduction of thermodynamic driving force for crystallization of near-critical size clusters is allowed for. This conclusion is of singular importance for the analysis of nucleation data. One last issue concerns the possible effect of elastic stresses on nucleation (Schmelzer \& Gutzow 2001). This, however, is a matter for further developments.

\section{Surface nucleation in silicate glasses}

As we have shown, ca. $90 \%$ of silicate glasses have $T_{\mathrm{gr}}>0.60$ and consequently display only surface crystallization. Close to or on interfaces, both thermodynamic and kinetic barriers for nucleation are typically lower than bulk values, causing a predominance of surface nucleation. However, its mechanisms and kinetics have drawn little attention and are not well understood so far. A detailed review of research aimed at understanding surface nucleation was recently published by Müller et al. (2000). Our attention here focuses mainly on the properties of nucleation sites, i.e. the mechanisms of surface nucleation.

\section{(a) Surface-nucleation kinetics}

Since surface nucleation occurs mostly on some active sites (e.g. tips, cracks, scratches and foreign particles), the kinetics of surface nucleation are governed by the exhaustion of these sites due to crystal nucleation and growth. Hence, the kinetic curve $N(t)$ generally reveals a saturation, $N(t) \rightarrow N_{\mathrm{s}}$ (figure $7 a$ ). As follows from the drastic drop of $N_{\mathrm{s}}$ (figure $7 b$, curve 1) with increasing temperature, potential nucleation sites can disappear during heat treatment, thus causing no nucleation. Different $N_{\mathrm{s}}(T)$ dependencies (figure $7 b$ ) also illustrate that different crystal phases (here, $\mathrm{X}$-phase and $\mu$-cordierite) can be induced by different kinds of nucleation sites and that quite a distinct nucleation kinetics occurs in each case.

The full $N(t)$-curve, including its saturation, is needed to calculate the nucleation rate. Owing to experimental limits (high $N_{\mathrm{s}}$ value, short saturation time due to high nucleation activity, difficulties of surface quality reproduction, etc.), such data are very rare. Often, the combination of a small number of nucleation sites and high activity leads to saturation before the achievement of visible sized crystals. In this case, Köster's (1988) method may be applied to estimate the nucleation kinetics. This post-mortem method is based on the analysis of crystal size distribution, caused by the difference in the time at which the crystals nucleated, which, in turn, leads to the time difference for growth.

The most comprehensive surface-nucleation kinetic data reported on so far were obtained for cordierite glass (Pannhorst 2000). A very important characteristic feature of surface-nucleation kinetics is the position of its maximum, $T_{\max }$, which considerably exceeds the glass-transition temperature and is often close to the temperature of maximum crystal growth rate. One should recall that, in the case of easily measured homogeneous volume nucleation, $T_{\max }$ is close to $T_{\mathrm{g}}$. A compilation of available 


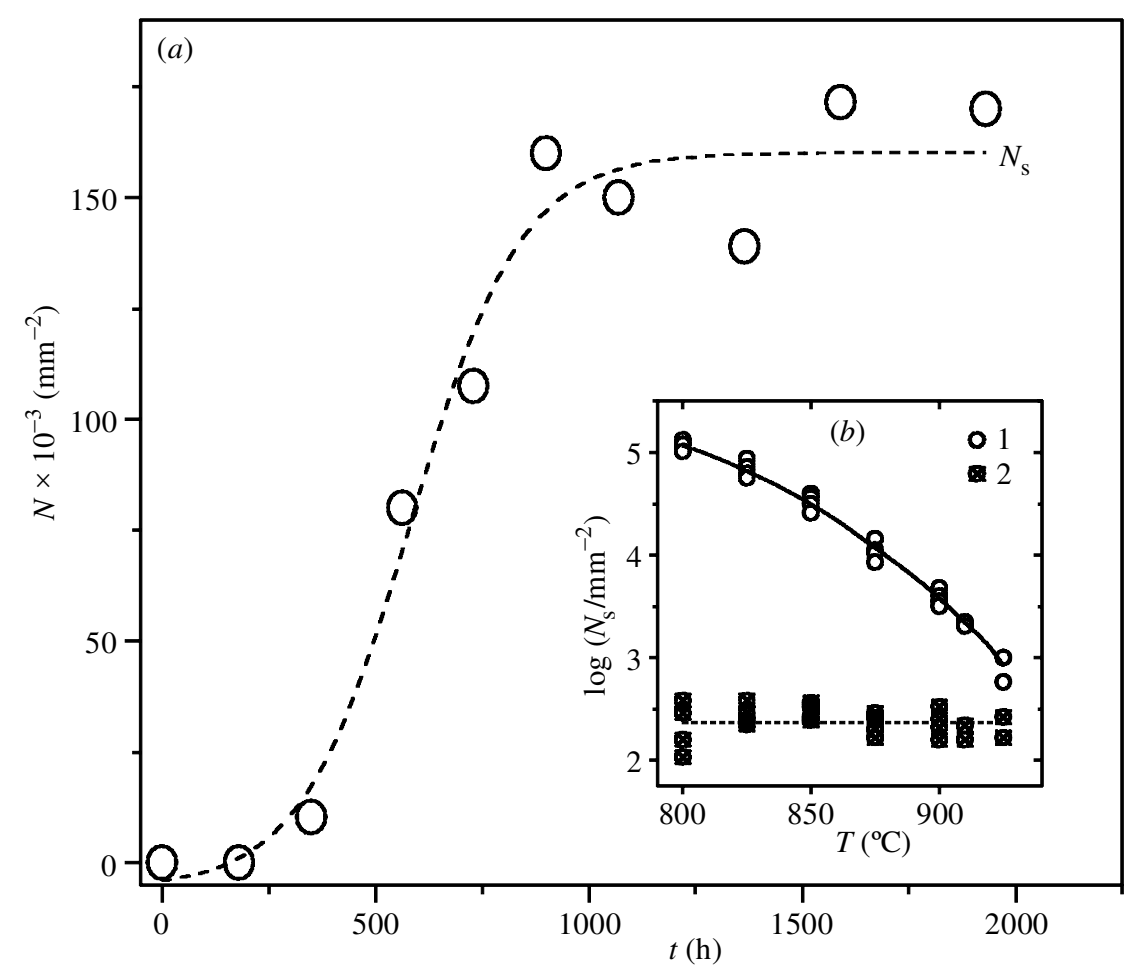

Figure 7. Nucleation kinetics on a cordierite glass surface polished by cerium oxide. (a) Number density of X-phase crystals against heat-treatment time at $800{ }^{\circ} \mathrm{C}$. (b) Saturation level of the number density of (1) X-phase and (2) $\mu$-cordierite crystals as a function of temperature. (Reproduced with permission from Filipovich et al. (1996).)

values of $\Delta T \equiv T_{\max }-T_{\mathrm{g}}$ for different glasses and types of surfaces show variations of $70-300{ }^{\circ} \mathrm{C}$. According to the CNT, the high temperature of the surface-nucleation maximum is caused mainly by a reduced thermodynamic barrier.

\section{(b) Surface nucleation sites}

Because surface-nucleation kinetics are governed by the presence of nucleation sites, the knowledge and understanding of their properties is a key factor in controlling surface crystallization. Various difficulties complicate the study of the nucleation mechanism. Experimental limitations preclude micro-analytical evidence of the former nucleation sites (e.g. healing of cracks, dissolution of dust particles). The experimental limits of the determination of $N(t)$ often hinder the measurement of the saturation number $N_{\mathrm{s}}$. This quantity must be known for a comparison of nucleation data from different systems and for the understanding of external parameters, such as surface conditions or annealing atmosphere. Several kinds of nucleation sites, differing in number density and activity, may occur simultaneously (Zanotto 1991b; Deubener et al. 1992; Filipovich et al. 1996). Additionally, the glass surface cannot be described using interior properties (e.g. due to unsaturated chemical bonds, evaporation, corrosion). Finally, the statistical nature of surface-nucleation sites (e.g. scratches, dust) causes data scatter, which can obscure the effect of many parameters, and requires 
the control of reproducible surface preparation and ambient annealing conditions. We consider here surface roughness, dust particles and annealing atmosphere.

\section{(c) Surface roughness}

Mechanical damage is known to promote surface nucleation of glass. Table 2, taken from Müller et al. (2000), summarizes surface-nucleation density $(N)$ for damaged glass surfaces, revealing a strong dependence of $N$ upon the degree of surface roughness. Smaller $N$, down to $c a .5 \times 10^{-8} \mu \mathrm{m}^{-2}$, frequently occur at freshly fractured surfaces. Low $N$ are also typical for fire-polished glass surfaces. Medium $N$, between $10^{-3} \mu \mathrm{m}^{-2}$ and $10^{-6} \mu \mathrm{m}^{-2}$, are evident on mechanically polished or fractured surfaces in a standard laboratory atmosphere. The data scatter is probably due to the presence of dust particles. Larger $N$ of up to $10^{-1} \mu \mathrm{m}^{-2}$ are reported for ground or glass powder surfaces.

\section{(d) Corners, edges and tips}

The nucleation mechanism related to mechanical damage has not been well understood to date. Tabata (1927) observed, in several silicate glasses, that surface nucleation is promoted by 'sharp edges or cicatrices'. Ernsberger (1962) showed, for plateglass, that crystals are preferably located at the cross-points (and, therefore, at the edges) of macro-cracks. Recently, it was confirmed, for cordierite, diopside, lithiaalumina-silica and float glasses, that sharp edges or tips are favoured nucleation sites (Müller et al. 1996; Schmelzer et al. 1995; Reinsch et al. 1994).

Surface crystals preferentially occur along surface edges caused by fracturing, along the edges of cracks caused by rapid cooling of glass ribbons or along diamond-made surface scratches. Sometimes, double chains of crystals form along the scratch edges. Glass particles dusted on a fractured glass surface, or those caused by sample fracturing, triggered crystallization at the contacted glass surface (Müller et al. 1992; Schmelzer et al. 1995; Fokin \& Zanotto 1999).

Under clean conditions, particles having the composition of the parent glass were detected at the centre of most of the very few crystals nucleated at the fractured surface of a cordierite glass. For a given glass powder sample (all particles were exposed to identical milling conditions), the surface-nucleation density, $N$, increased with decreasing particle size because small glass particles provide a larger number of sharp edges per surface area (Müller et al. 1995). For $\mu$-cordierite crystals nucleating on mechanically damaged cordierite glass surfaces, other experiments show that $N$ is correlated to the number density of surface edges or tips, whereas the condition of damaging exerts a minor influence. A controlled reduction of $N$ can be obtained by surface smoothing. Thus, HF etching of ground surfaces prior to the thermal treatment sharply decreases both the number of these edges and $N$. The value of $2 l$ and the mean linear distance between surface tips (detected by mechanical surfaceprofiling) are reduced quite similarly (Müller et al. 1996). Accordingly, polishing of SiC-ground glass surfaces reduces $N$ with polishing time, approaching invariance at $t>5 \mathrm{~min}$ (Reinsch et al. 1999). Optical and electron micrographs show that, for $t>5 \mathrm{~min}$, all the tips and edges of the ground surface are eliminated. 


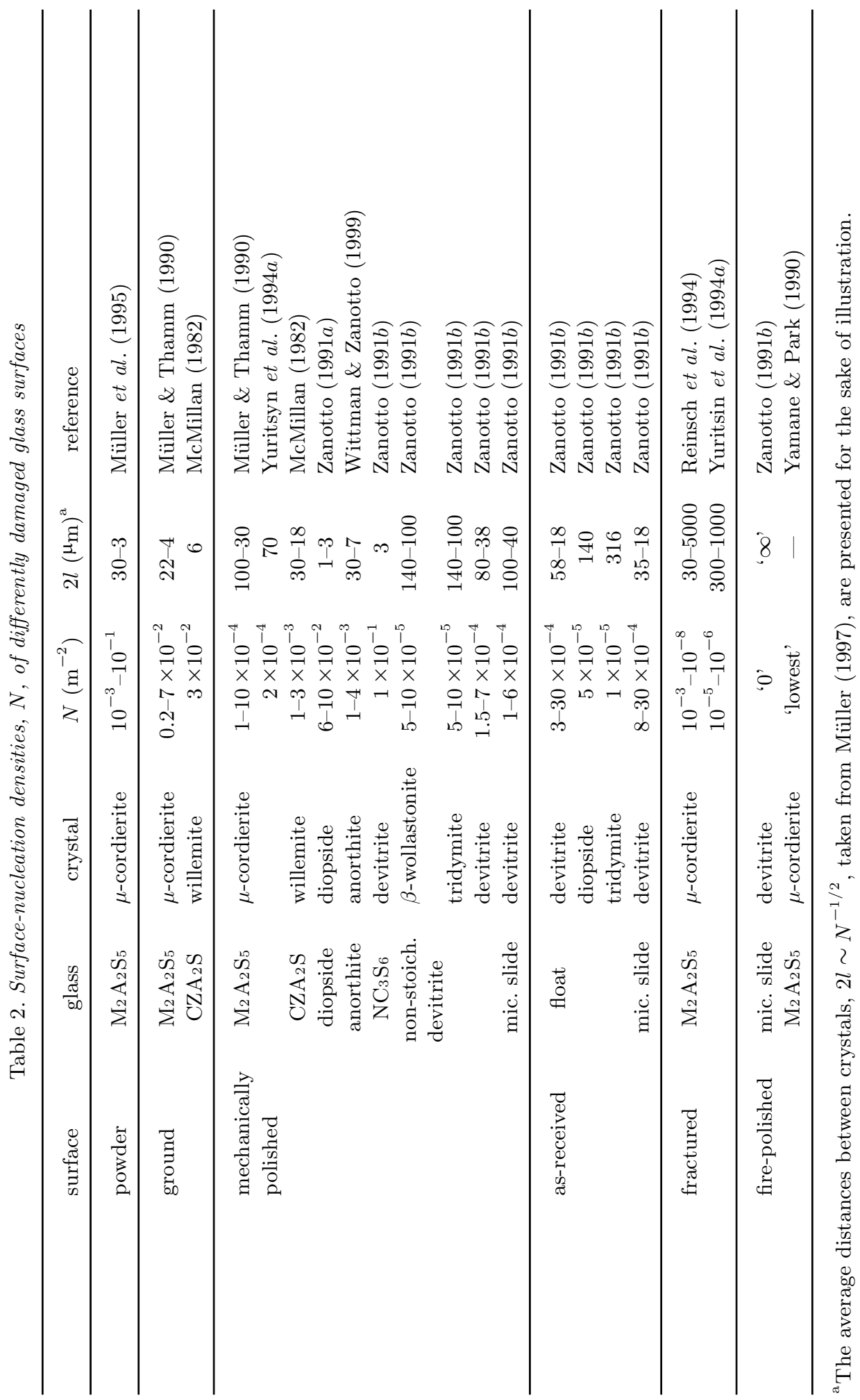




\section{(e) The effect of elastic stresses}

A simple nucleating mechanism of convex edges or tips was suggested by Schmelzer et al. (1993), based on the viscous elastic nature of glass-forming melts. These authors have shown that elastic stresses caused by the growing crystalline clusters, whose density deviates from that of liquid, can considerably hinder nucleation. Calculations are based on equation (5.1), which describes the elastic energy required for the addition of one monomer of volume, $v_{\mathrm{C}}$, in the interior of the glass, $\Phi_{0}$ :

$$
\Phi_{0}=\left(\frac{E}{9(1-\gamma)}\right) \delta^{2} v_{\mathrm{C}}
$$

The term $E / 9(1-\gamma)$ represents the effect of the elastic properties ( $E$ is Young's modulus, $\gamma$ is Poisson's number) and $\delta=\left(\rho_{\mathrm{C}}-\rho_{G}\right) / \rho_{G}$ is the relative density difference between the melt and the crystal. Neglecting stress relaxation, all elastic energy is accumulated to the cluster size $\alpha$ according to $\Phi(\alpha)=\alpha \Phi_{0}$. Hence, the molar free energy change of crystallization is $\Delta \mu^{(\varepsilon)}=\Delta \mu-N_{\mathrm{A}} \Phi_{0}$ and the corrected volume nucleation rate, $I^{(\varepsilon)}$, is given by (Schmelzer et al. 1993)

$$
I^{(\varepsilon)}=I \exp \left\{-\left(\left[\left(\frac{\Delta \mu}{\Delta \mu^{(\varepsilon)}}\right)^{2}-1\right] W\right)\left(\frac{1}{k T}\right)\right\} .
$$

As $\Phi_{0}$ decreases with the ratio between the surface distance and the cluster radius, nucleation is easier close to the surface than in the interior, due to the less-intensive stress field in its vicinity (Schmelzer et al. 1995). This effect of the elastic stresses is greater for sharp convex surface curvatures such as surface edges or tips.

This hypothesis offers a good explanation of all of the experimental results mentioned. Other observations support this assumption more directly.

(i) Large cracks caused by quenching of cordierite glass ribbons were completely healed during a thermal treatment (Schmelzer et al. 1995; Müller et al. 1992). The former tips did not cause nucleation. This effect confirms the model proposed by Schmelzer et al. (1993) because the elastic response of the glass matrix at the crack tips is nearly the same as for any other point in the interior.

(ii) In contrast to the sharp edges of fractured glass surfaces, smooth or wavy surface curvature causes less-intensive surface nucleation (Müller et al. 1996). Schmelzer et al. (1995) have shown that, correspondingly, the energy of elastic deformation depends on the angle of convex surface tips or edges.

(iii) The nucleation activity observed along former edges of cracks (Schmelzer et al. 1995), scratches or Vickers indentations is greater for the largest values of $\delta$. The nucleation on two glass surfaces after Vickers indentation were studied by Reinsch et al. (1999). Less numerous cristobalite crystals grow at the edges of the indentation on the float glass surface $(\delta \approx 10 \%)$ than diopside crystals growing at the indentation edges on the diopside glass surface $(\delta \approx 15 \%)$. In the case of $\mu$-cordierite growing on the cordierite glass surface $(\delta \approx 2 \%)$, indenting did not cause additional surface nucleation. 


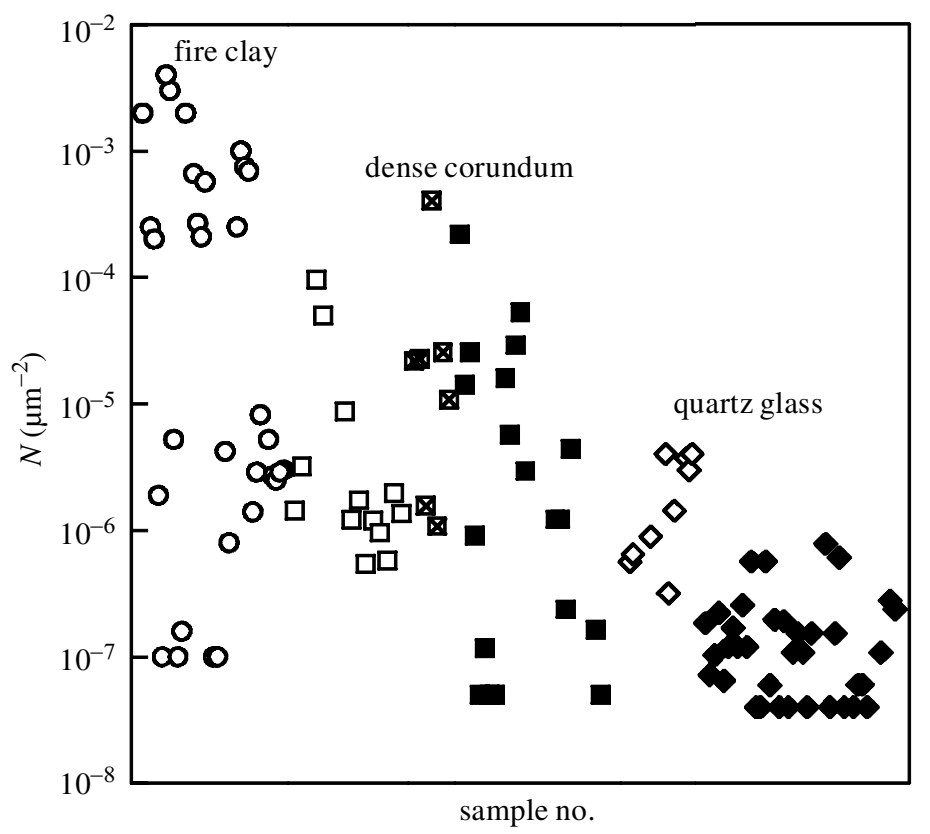

Figure 8. Nucleation density of $\mu$-cordierite at cordierite glass surfaces, fractured and annealed under different conditions. $\bigcirc$ denotes fire-clay furnace, air; $\square$, corundum tube furnace, air; $\otimes$, corundum tube furnace, dust protected; $\mathbf{0}$, corundum tube furnace, dry air; $\downarrow$, quartz-glass tube furnace, air; $\diamond$, quartz-glass tube furnace, vacuum. (Reproduced with permission from Müller (1997).)

\section{(f) Solid particles}

In the case of smooth glass surfaces (as-received, polished or fractured), $N$ is strongly affected by the presence of solid particles. As early as 1739, Réamur triggered surface nucleation of glassware by contamination with foreign solid particles. Particles of pre-crystallized glass were used to increase crystallization of powdered (Rabinovich 1979) or solid glasses (Ding et al. 1994). Figure 8 shows that there is a strong scatter in $N$ due to the random occurrence of dust for different furnace materials, dust protection, or vacuum. A scatter of seven orders of magnitude in $N$ occurred in fire-clay furnaces, while this scatter was smaller using a gas-dense quality corundum furnace and much smaller when silica glass was used as the furnace material.

The impact of solid foreign particles is not merely dependent on their number but is also determined by their nucleating activity. For example, microscopic observations show that numerous solid particles resting on glass surfaces during the crystallization treatment did not cause nucleation. The nucleating efficiency of solid metal substrates, $\phi$, has been studied for heterogeneous volume nucleation (Gutzow 1980a,b). A comprehensive model is given in Dobreva \& Gutzow (1993), connecting $\phi$ with the cohesion forces in the substrate and lattice misfit. The activity of foreign surface particles should follow that general concept. However, additional effects of the ambient atmosphere must be expected. 
Oxide dust particles, which are in most cases thermally stable, were found to provide active nucleating substrates for $\mu$-cordierite. Thus, $\mathrm{ZrO}_{2}$, known for its thermal stability, was found to be the most efficient surface-nucleation catalyser. Nucleating activity was affected by its crystal morphology, indicating epitaxial phenomena. Similarly, the nucleation activity of dusted $\mu$-cordierite, $\alpha$-cordierite, quartz and fire-clay powders (the latter is a mixture of corundum, $\alpha$-cordierite, mullite and quartz) may be caused by the lattice misfit between these powdered crystals and cordierite crystal. Correspondingly, larger $N$ are evident for agate (quartz) ball-milled cordierite glass powders (Müller et al. 1995) because of the slight lattice misfit with cordierite. We note, however, that the stability (and nucleation activity) of oxide particles can be limited by dissolution into liquid cordierite. Thus, dusting with $\mathrm{TiO}_{2}$ and $\mathrm{WO}_{3}$ reduces $N$, as is the case of dusting with unstable compounds such as $\mathrm{W}$ and WC.

Non-oxide dust particles, in most cases less thermally stable, did not increase $N$ except in a vacuum ( $p<10^{-4}$ mbar), where better oxidation stability is guaranteed. The inertness of $\mathrm{SiC}$ and $\mathrm{Si}_{3} \mathrm{~N}_{4}$ is probably due to the formation of an amorphous $\mathrm{SiO}_{2}$ surface layer. The increased nucleation activity of these particles under vacuum supports this explanation. In the case of the larger concentrations of unstable particles (W, WC, $\mathrm{B}_{4} \mathrm{C}$ or less-stable oxides such as $\mathrm{WO}_{3}$ and $\mathrm{B}_{2} \mathrm{O}_{3}$ ), a rippled glass surface and the occurrence of foreign crystalline phases were observed, indicating chemical interaction with the liquid (dissolution). In the worst case, the latter effect can essentially change the composition of the glass surface layer. Thus, intensive dusting with $\mathrm{B}_{4} \mathrm{C}$ triggered crystallization of needle-like foreign crystals and caused a rippled surface morphology. These effects can be explained assuming an enrichment of $\mathrm{B}_{2} \mathrm{O}_{3}$ in the near-surface area due to oxidation of $\mathrm{B}_{4} \mathrm{C}$ and to the well-known decrease in surface tension by the addition of $\mathrm{B}_{2} \mathrm{O}_{3}$ (Scholze 1977). This observation is confirmed by the chemical inertness of $\mathrm{B}_{4} \mathrm{C}$ under vacuum. $\mathrm{W}$ and $\mathrm{WC}$ show a similar inertness. Their oxidation is most probably followed by dissolution of the oxide into the melt, which modifies the surface morphology. A rippled surface and the total absence of $\mu$-cordierite were also caused by dusting with $\mathrm{K}_{2} \mathrm{SO}_{4}$. X-ray analyses of a heat-treated mixture of $\mathrm{K}_{2} \mathrm{SO}_{4}$ and cordierite glass powder showed leucite as the crystal phase (Müller et al. 2000), indicating dissolution.

In summary, the nucleating activity of solid sites is predominantly limited by their chemical stability. Chemical reactions with the glass and with the ambient atmosphere can decrease their nucleating efficiency. Accordingly, all thermally stable furnace-tube materials (e.g. fire clay or alumina) turned out, unfortunately, to provide the most active nucleation seeds. The same holds true for oxide-milling materials (Müller et al. 1995).

\section{(g) Ambient atmosphere}

A strong effect of ambient gases (e.g. water vapour) on surface crystallization is frequently stressed in the older literature. The effect, however, is more important on the crystal's growth than on the number of nucleation sites (Müller et al. 2000). Experiments under glove-box conditions showed no effect of ambient humidity on the surface-nucleation density of $\mu$-cordierite, while the crystal growth rate substantially increased with increasing humidity (Müller et al. 1996). It should also be noted that very low $N$, down to $N \approx 10^{-8} \mu \mathrm{m}^{-2}$, occasionally occur for freshly fractured surfaces and that such small $N$ are typical for fire-polished surfaces, even in air atmosphere. 


\section{Overall conclusions}

The internal homogeneous nucleation rates of silicate glasses sharply decrease and the induction times increase with the $T_{\mathrm{g}} / T_{\mathrm{L}}$ ratio. Only systems that have $T_{\mathrm{g}} / T_{\mathrm{L}}<0.58$ display measurable internal nucleation rates on a laboratory time-scale and can be used to analyse nucleation theories.

Using the capillarity approximation, numerous tests of the CNT have demonstrated that the theory fails to quantitatively describe the nucleation rates in glasses. Possible explanations for this failure, such as the use of induction time instead of viscosity to account for molecular transport, the precipitation of metastable phases, compositional shifts of the crystal nuclei, and the possible variation of the surface energy with nucleus size and temperature, were tested and discussed. Of these, the last two appear to be the most relevant. The possible effect of elastic strain is a matter for future studies.

Surface nucleation depends strongly on surface quality: tips, cracks and scratches, elastic stresses, foreign particles and surrounding atmosphere. Despite the fact that the mechanisms of surface nucleation are still not fully understood, some of the key factors are now known, thus allowing for control of the surface-nucleation density and sintering with concurrent crystallization. This improved knowledge has been used in the manufacture of sintered glass ceramics.

The authors thank several collaborators from over the past five years: M. C. Weinberg, J. W. Schmelzer, P. C. Soares Jr, M. O. Prado, E. B. Ferreira, N. S. Yuritsyn and O. V. Potapov. Stimulating discussions on surface crystallization with R. Müller, G. Völksch, W. Pannhorst, W. Höland (members of Technical Committee 7 of the ICG) are deeply appreciated. We also thank P. F. James, L. Granasy and K. Kelton for reviewing the manuscript. E.D.Z. acknowledges the funding provided by CNPq, Cyted, PRONEX and FAPESP (Brazil) in the period 1998-2002, when most of the studies were performed.

\section{References}

Burgner, L. L., Lucas, P., Weinberg, M. S., Soares Jr., P. C. \& Zanotto, E. D. 2000 On the persistence of metastable crystal phases in lithium disilicate glass. J. Non-Cryst. Solids $\mathbf{2 7 4}$, 188-194.

Deubener, J. 2000 Compositional onset of homogeneous nucleation in ( $\mathrm{Li}, \mathrm{Na}$ ) disilicate glasses. J. Non-Cryst. Solids 274, 195-203.

Deubener, J., Brückner, R. \& Hessenkemper, H. 1992 Nucleation and crystallization kinetics on float glass surfaces. Glastech. Ber. Glass Sci. Technol. 65, 256-266.

Deubener, J., Brückner, R. \& Sternizke, M. 1993 Induction time analysis of nucleation and crystal growth in di- and metasilicate glasses. J. Non-Cryst. Solids 163, 1-12.

Ding, Y., Osaka, A. \& Miura, Y. 1994 Enhanced surface crystallization of $\beta$-barium borate on glass due to ultrasonic treatment. J. Am. Ceram. Soc. 77, 749-752.

Dobreva, A. \& Gutzow, I. 1993 Activity of substrates in the catalyzed nucleation of glass forming melts. J. Non-Cryst. Solids 162, 1-12.

Ernsberger, F. M. 1962 A study of the origin and frequency of occurrence of Griffith microcracks on glass surfaces. In Proc. VI Int. Congr. on Glass, Washington, DC, USA, pp. 511-523.

Filipovich, V. N., Kalinina, A. M. \& Fokin, V. M. 1983 Relation between the structure of glass and its ability to internal crystallization. In Stekloobraznoe sostoyanie (ed. E. A. PoraiKoshits), pp. 124-131. Leningrad: Nauka (In Russian.)

Filipovich, V. N., Fokin, V. M., Yuritsin, N. S. \& Kalinina, A. M. 1996 Crystal nucleation on the glass surface: theory and experiment. Thermochim. Acta 280-281, 205-222. 
Fokin, V. M. \& Zanotto, E. D. 1999 Surface and volume nucleation and growth in $\mathrm{TiO}_{2}$-cordierite glasses. J. Non-Cryst. Solids 246, 115-127.

Fokin, V. M. \& Zanotto, E. D. 2000 Crystal nucleation in silicate glasses: the temperature and size dependence of crystal/liquid surface energy. J. Non-Cryst. Solids 265, 105-112.

Fokin, V. M., Potapov, O. V., Chinaglia, C. R. \& Zanotto, E. D. 1999 The effect of pre-existing crystals on the crystallization kinetics of a soda-lime-silica glass: the courtyard phenomenon. J. Non-Cryst. Solids 258, 180-186.

Fokin, V. M., Zanotto, E. D. \& Schmelzer, J. W. P. 2000 Method to estimate crystal/liquid surface energy by dissolution of subcritical nuclei. J. Non-Cryst. Solids 278, 24-34.

Fokin, V. M., Zanotto, E. D. \& Schmelzer, J. W. P. 2002a Homogeneous nucleation versus glass-transition temperature in silicate glasses. J. Non-Cryst. Solids (In the press.)

Fokin, V. M., Potapov, O. V., Zanotto, E. D., Ugolkov, V. L., Spiandorello, F. M. \& Pevzner, B. Z. $2002 b$ Crystallization of solid solutions in $\mathrm{Na}_{2} \mathrm{O} .2 \mathrm{CaO} .3 \mathrm{SiO}_{2}$ glasses. (Submitted.)

Freiman, S. W. \& Hench, L. L. 1968 Kinetics of crystallization in $\mathrm{Li}_{2} \mathrm{O}-\mathrm{SiO}_{2}$ glasses. J. Am. Ceram. Soc. 51, 382-387.

Granasy, L. \& James, P. F. 1998 Nucleation of oxide glasses: comparison of theory and experiment. Proc. R. Soc. Lond. A 454, 1745-1766.

Granasy, L. \& James, P. F. 1999a Transient nucleation in oxide glasses: the effect of interface dynamics and subcritical cluster population. J. Chem. Phys. 111, 737-749.

Granasy, L. \& James, P. F. 1999 b Non-classical theory of crystal nucleation: application to oxide glasses. J. Non-Cryst. Solids 253, 210-230.

Granasy, L. \& James, P. F. 2000 Nucleation and growth in cluster dynamics: a quantitative test of the classical kinetic approach. J. Chem. Phys. 113, 9810-9821.

Gutzow, I. 1980 a Induced crystallization of glass-forming systems. Part 1. Contemp. Phys. 21, 121-137.

Gutzow, I. 1980 b Induced crystallization of glass-forming systems. Part 2. Contemp. Phys. 21, $243-263$.

Gutzow, I. \& Schmelzer, J. 1995 The vitreous state: thermodynamics, structure, rheology and crystallization, p. 469. Springer.

Gutzow, I., Kashiev, D. \& Avramov, I. 1985 Nucleation and crystallization in glass-forming melts: old problems and new questions. J. Non-Cryst. Solids 73, 477-499.

Hench, L. L., Frieman, S. W. \& Kinser, D. L. 1971 The early stages of crystallization in a $\mathrm{Li}_{2} \mathrm{O}-\mathrm{SiO}_{2}$ glass. Phys. Chem. Glass. 12, 50-63.

James, P. F. 1982 Nucleation in glass-forming systems. In Advances in ceramics (ed. J. H. Simmons, D. R. Uhlmann, \& G. H. Beall), pp. 1-48. Columbus, OH: American Ceramic Society.

James, P. F. 1989 Volume nucleation in silicate glasses. In Glasses and glass-ceramics (ed. M. H. Lewis), pp. 59-105. London: Chapman \& Hall.

James, P. F. \& Keown, S. R. 1974 Study of crystallization in lithium silicate glasses using high-voltage electron microscopy. Phil. Mag. 30, 789-801.

Joseph, L. \& Pye, L. D. 1986 Nucleation studies in lithium disilicate glass. In Proc. 14 th Int. Cong. on Glass, pp. 358-365. New Delhi, India: Indian Ceramic Society.

Köster, U. 1988 Surface crystallization of metallic glasses. Mater. Sci. Engng A 97, 233-239.

Lewis, M. H., Metacalf-Johansen, J. \& Bell, P. S. 1979 Crystallization mechanisms in glassceramics. J. Am. Ceram. Soc. 62, 278-288.

McMillan, P. W. 1982 The crystallisation of glasses. J. Non-Cryst. Solids 52, 67-76.

Manrich, S. \& Zanotto, E. D. 1995 Crystal nucleation in silicate glasses analyzed by different forms of the classical theory. Cerâmica 41, 105-115. (In Portuguese.) 
Miyazawa, Y. \& Pound, G. M. 1974 Homogeneous nucleation of crystalline gallium from liquid gallium. J. Cryst. Growth 23, 45-57.

Müller, R. 1997 Surface nucleation in cordierite glass. J. Non-Cryst. Solids 219, 110-118.

Müller, R. \& Thamm, D. 1990 Surface-induced nucleation of cordierite glass. In Proc. 4th Int. Otto-Schott Colloq, Friedrich-Schiller-Universität Jena, p. 86. Jena: Friedrich-SchillerUniversität.

Müller, R., Thamm, D. \& Pannhorst, W. 1992 On the nature of nucleation sites at cordierite glass surfaces. Bol. Soc. Esp. Ceram. Vid. C 31, 105-111.

Müller, R., Reinsch, S., Sojref, R. \& Gemeinert, M. 1995 Nucleation at cordierite glass powder surface. In Proc. XVII Int. Congr. on Glass, Bejing, People's Republic of China, pp. 564-569. Bejing: International Academic Publishers.

Müller, R., Reinsch, S., Völksch, G. \& Heide, K. 1996 Nucleation sites at cordierite glass surfaces. Ber. BunsenGes. Phys. Chem. 100, 1438-1442.

Müller, R., Zanotto, E. D. \& Fokin, V. M. 2000 Surface crystallization of silicate glasses: nucleation sites and kinetics. J. Non-Cryst. Solids 274, 208-231.

Pannhorst, W. 2000 Surface nucleation: collection of papers (ed. W. Pannhorst). Charleroi, Belgium: International Commission on Glass.

Potapov, O. V., Fokin, V. M., Ugolkov, V. L., Suslova, L. Y. \& Filipovich, V. N. 2000 Influence of $\mathrm{Na}_{2} \mathrm{O}$ content on the nucleation kinetics in glasses of compositions close to $\mathrm{Na}_{2} \mathrm{O} .2 \mathrm{CaO} .3 \mathrm{SiO}_{2}$ stoichiometry. Sov. J. Glass Phys. Chem. 26, 39-47.

Prado, M. O., Fredericci, C. \& Zanotto, E. D. 2002 Glass sintering with concurrent crystallization. Part 2. Non-isothermal sintering of jagged polydispersed particles. Phys. Chem. Glass. 43, 230-245.

Rabinovich, E. M. 1979 Crystallization and thermal expansion of solder glasses in the PbO$\mathrm{B}_{2} \mathrm{O}_{3}-\mathrm{ZnO}$ system. Ceram. Bull. 58, 595-605.

Réamur, R. 1739 Art de faire une nouvelle espece de porcelaine. Mem. Acad. R. Sci. Paris XX, 370-388.

Reinsch, S., Müller, R. \& Pannhorst, W. 1994 Active nucleation sites at cordierite glass surfaces. Glastech. Ber. Glass Sci. Technol. C 67, 432-435.

Reinsch, S., Müller, R., Völksch, G. \& Heide, K. 1999 Nucleation sites at silicate glass surfaces. In Proc. 5th ESG Conf. on Glass Science and Technology. Prague: Czech Glass Society.

Rusanov, A. I. 1978 Phasengleichgewichte und Grenzflächenerscheinungen, p. 465. Berlin: Akademie.

Schmelzer, J. W. P. \& Gutzow, I. S. 2001 Elastic stresses, stress relaxation, and crystallisation. Proc. XIX Int. Congr. on Glass, vol. 2, pp. 11-12. Sheffield, UK: Society of Glass Technology.

Schmelzer, J. W. P., Pascova, R., Müller, J. \& Gutzow, I. 1993 Surface-induced devitrification of glasses: the influence of elastic strains. J. Non-Cryst. Solids 162, 26-39.

Schmelzer, J. W. P., Müller, J., Gutzow, I., Pascova, R., Müller, R. \& Pannhorst, W. 1995 Surface energy and structure effects on surface crystallization. J. Non-Cryst. Solids 183, $215-233$.

Schmelzer, J. W. P., Schmelzer Jr., J. \& Gutzow, I. 2000 Reconciling Gibbs and van der Waals: a new approach to nucleation theory. J. Chem. Phys. 112, 3820-3831.

Scholze, H. 1977 Glas - Natur, Struktur und Eigenschaften, p. 342. Springer.

Soares Jr, P. C. 1997 Early stages of crystallisation of lithium disilicate glasses. MSc dissertation, Federal University of São Carlos, São Carlos, Brazil. (Available online at www.nit.ufscar.br/lamav.)

Soares Jr, P. C., Zanotto, E. D. \& Jain, H. 2002 TEM/XRD study LS $_{2}$ glass crystallisation. J. Non-Cryst. Solids (Submitted.).

Tabata, K. 1927 On the causes of the surface devitrification of glasses. J. Am. Ceram. Soc. 10, $6-22$.

Tolman, R. C. 1949 The effect of droplet size on surface tension. J. Chem. Phys. 17, 333-337. 
Turnbull, D. 1952 Kinetics of solidification of supercooled liquid mercury droplets. J. Chem. Phys. 20, 411-424.

Weinberg, M. C. \& Zanotto, E. D. 1989 Re-examination of the temperature dependence of the classical nucleation rate: homogeneous crystal nucleation in glass. J. Non-Cryst. Solids 108, 99-108.

Wittman, E. \& Zanotto, E. D. 1999 Surface nucleation and growth in anorthite glass. J. NonCryst. Solids 271, 94-99.

Yamane, M. \& Park, W. 1990 Effect of surface condition on nucleation and crystallization of a cordierite glass. Presentation at TC 7 Meeting, International Commision on Glass, Jena, Germany.

Yuritsyn, N. S., Fokin, V. M., Kalinina, A. M. \& Filipovitch, V. N. 1994a Crystal nucleation and growth in the surface crystallization of cordierite glass. Sov. J. Glass Phys. Chem. 20, $116-124$.

Yuritsyn, N. S., Fokin, V. M., Kalinina, A. M. \& Filipovitch, V. N. $1994 b$ Crystal nucleation in cordierite glass: kinetics and theoretical model. Sov. J. Glass Phys. Chem. 20, 125-132.

Zanotto, E. D. 1987 Isothermal and adiabatic nucleation in glass. J. Non-Cryst. Solids 89, 361-371.

Zanotto, E. D. 1991 a Surface nucleation in a diopside glass. J. Non-Cryst. Solids 130, 217-219.

Zanotto, E. D. $1991 b$ Surface crystallization kinetics in soda-lime-silica glasses. J. Non-Cryst. Solids 129, 183-190.

Zanotto, E. D. 1997 Metastable phases in lithium disilicate glasses. J. Non-Cryst. Solids 219, $42-48$.

Zanotto, E. D. \& Leite, M. L. G. 1996 The nucleation mechanism of lithium disilicate glass revisited. J. Non-Cryst. Solids 202, 145-152.

Zanotto, E. D. \& Prado, M. O. 2001 Isothermal sintering with concurrent crystallization of monodispersed and polydispersed glass particles. Part 1. Phys. Chem. Glass. 42, 191-198.

Zanotto, E. D. \& Weinberg, M. C. 1989 Trends in homogeneous crystal nucleation in glass. Phys. Chem. Glass. 30, 186-192.

\section{Discussion}

A. Boccaccini (Department of Materials, Imperial College of Science, Technology and Medicine, London, $U K$ ). You presented a very interesting overview of recent studies on internal and surface nucleation in glass. The experimental results you show are obtained from glass samples having large dimensions in comparison with the scale of crystals nucleated. It would be interesting to extend your findings to consider the behaviour of nanoparticles of glass having a very high surface-area/volume ratio. Is it possible to separate the phenomenon of internal and surface nucleation in nanoparticles experimentally?

E. D. ZanotTo. In order to separate internal and surface nucleation in glass nanoparticles one might try a few experiments. We have shown in this paper that internal (homogeneous) nucleation is experimentally observed in bulk glasses if $T_{\mathrm{g}} / T_{\mathrm{L}}<0.58$ (temperatures in kelvin). At such high undercoolings the expected critical nucleus radius is only $c a .1 \mathrm{~nm}$, thus we believe that internal nucleation could occur in particles 50-100 nm in diameter. At such small scale, however, the problem is how to detect some crystals after they have grown to a few tens of nanometres, internally or on the particles surface. One could try to use TEM methods for direct observation, or non-isothermal techniques, such as differential thermal analysis or differential scanning calorimetry, for indirect examination. In the latter case, 
comparison of the height and temperature of the crystallization peaks obtained for identical experimental conditions, for nanoparticles and millimetric particles of the same glass, could give important clues. For instance, if internal crystallization predominates, the traces of the two widely differing particle sizes would be quite similar and vice versa. 